\title{
Simultaneous analyses and applications of multiple fluorobenzoate and halide tracers
} in hydrologic studies

\author{
Qinhong $\mathrm{Hu}^{*}$ and Jean E. Moran
}

\author{
Chemistry and Materials Science Directorate \\ Lawrence Livermore National Laboratory \\ 7000 East Avenue, MS L-231 \\ Livermore, CA 94550
}

Prepared for

Hydrological Processes

January 30, 2004

*Corresponding author (phone: 925-422-6774; fax: 925-422-3160; e-mail: hu7@llnl.gov)

Approved for public release; further dissemination unlimited 


\section{DISCLAIMER}

This document was prepared as an account of work sponsored by an agency of the United States Government. Neither the United States Government nor the University of California nor any of their employees, makes any warranty, express or implied, or assumes any legal liability or responsibility for the accuracy, completeness, or usefulness of any information, apparatus, product, or process disclosed, or represents that its use would not infringe privately owned rights. Reference herein to any specific commercial product, process, or service by trade name, trademark, manufacturer, or otherwise, does not necessarily constitute or imply its endorsement, recommendation, or favoring by the United States Government or the University of California. The views and opinions of authors expressed herein do not necessarily state or reflect those of the United States Government or the University of California, and shall not be used for advertising or product endorsement purposes.

This work was performed under the auspices of the U. S. Department of Energy by the University of California, Lawrence Livermore National Laboratory under Contract No. W7405-Eng-48.

This report has been reproduced directly from the best available copy.

Available to DOE and DOE contractors from the

Office of Scientific and Technical Information

P.O. Box 62, Oak Ridge, TN 37831

Prices available from (423) 576-8401

http://apollo.osti.gov/bridge/

Available to the public from the

National Technical Information Service

U.S. Department of Commerce

5285 Port Royal Rd., Springfield, VA 22161

http://www.ntis.gov/

OR

Lawrence Livermore National Laboratory

Technical Information Department’s Digital Library

http://www.llnl.gov/tid/Library.html 


\section{ABSTRACT}

An analytical method that employs ion chromatography has been developed to more fully

3 exploit the use of fluorobenzoic acids (FBAs) and halides as hydrologic tracers. In a single run,

4 this reliable, sensitive, and robust method can simultaneously separate and quantify halides

5 (fluoride, chloride, bromide, and iodide) and up to seven FBAs from other common groundwater

6 constituents (e.g., nitrate and sulfate). The usefulness of this ion chromatographic (IC) analytical

7 method is demonstrated in both field and laboratory tracer experiments. Field experiments in

8 unsaturated tuff featuring fractures or a fault show that this efficient and cost-effective method

9 helps achieve the objectives of tracer studies that use multiple FBAs and/or diffusivity tracers

10 (simultaneous use of one or more FBA and halide).

11 The field study examines the hydrologic response of fractures and the matrix to different

12 flow rates and the contribution of matrix diffusion in chemical transport. Laboratory tracer

13 experiments with eight geologic media from across the United States—mostly from Department

14 of Energy facilities where groundwater contamination is prevalent and where subsurface

15 characterization employing tracers has been ongoing or is in need—reveal several insights about

16 tracer transport behavior: (1) Bromide and FBAs are not always transported conservatively. (2)

17 The delayed transport of these anionic tracers is likely related to geologic media characteristics,

18 such as organic matter, $\mathrm{pH}$, iron oxide content, and clay mineralogy. (3) Any use of iodine as a

19 hydrologic tracer should take into account the different sorption behaviors of iodide and iodate

20 and the possible conversion of iodine's initial chemical form. (4) The transport behavior of

21 potential FBA and halide tracers under relevant geochemical conditions should be evaluated

22 before beginning ambitious, large-scale field tracer experiments.

23 Key Words: tracers, fluorobenzoic acid, groundwater, transport, halides, ion chromatography. 


\section{INTRODUCTION}

Many laboratory and field experiments investigating hydrologic processes in the

3 subsurface have obtained crucial data through the application of tracer(s) (Davis et al., 1980).

4 Traditionally, halides (e.g., fluoride, chloride, bromide, and iodide) have been used as water

5 tracers. However, over the past 20 years, the use of fluorobenzoic acids (FBAs) as water tracers

6 has received considerable attention in numerous studies investigating water flow and solute

7 transport in both porous and fractured media (e.g., Hydro Geo Chem, 1986; Bowman and

8 Gibbens, 1992; Boggs and Adams, 1992; Pearson et al., 1996; Seaman, 1998; Dahan et al.,

9 1999; Hu et al., 2001; Hu et al., 2002; Nelson et al., 2003; Reimus et al., 2003; Mayes et al.,

10 2003). FBAs are attractive tracers because they do not occur naturally, are detectable at low

11 concentrations, are resistant to degradation, and low aquatic toxicity (Bowman and Gibbens,

12 1992; McCarthy et al., 2000). In addition, since the aqueous diffusion coefficient of an FBA is

13 about 3 times smaller than those of tritium and halides, a diffusivity-tracer approach has been

14 exploited with a simultaneous use of FBA and tritium or halide tracers when studying hydrologic

15 processes. The diffusivity-tracer test has been employed to investigate solute dispersion and

16 diffusive mass transfer between fast- and slow-moving flow regions (e.g., Hu and Brusseau,

17 1995; Callahan et al. 2000; Hu et al., 2002; Reimus et al., 2003; Salve et al., in press).

Multiple FBA and halide tracers can be applied either simultaneously or sequentially.

19 Depending upon the number and position of the fluorine atom in the benzene ring, there are 16

20 FBA isomers or derivatives that exhibit similar physicochemical properties and environmental

21 behavior. (Additional FBA isomers exist when the hydrogen atom in the benzene ring is

22 substituted by a chlorine atom or a fluoromethyl functional group.) This wide variety of FBA

23 isomers is especially useful for studies where other common anionic tracers, such as bromide and 
1 chloride, are not suitable and for research objectives that require multiple tracers with similar

2 characteristics.

3 For example, a field study at the northern Negev Desert, Israel, used seven FBA isomers

4 to examine water flow through a discrete natural fracture in unsaturated chalk (Dahan et al.,

5 1999). One isomer was added to each of the seven percolation ponds, which were installed

6 sequentially along the exposed fracture, to delineate flow path along the fracture plane (Dahan et

7 al., 1999). Another study involving field tracer-transport tests in unsaturated fractured tuff at

8 Yucca Mountain, Nevada, applied four FBA isomers, each at a different fluid release rate (Hu et

9 al., 2001). The tracer results showed significant variability in the hydrologic response of the

10 fractures and the matrix. Under high release rates, the fractures acted as the predominant flow

11 pathways, with limited fracture-matrix interaction. Under low release rates, fracture flow was

12 less dominant, with a noticeable contribution from matrix flow.

13 With $\mathrm{p} K_{\mathrm{a}}$ values that range between 2.7 and 3.8, FBAs exist predominantly as anionic

14 species under the neutral $\mathrm{pH}$ condition of normal groundwater with $2 \mathrm{pH}$ units above the $\mathrm{p} K_{\mathrm{a}}$.

15 The transport behavior of FBAs in many subsurface media has been observed to be nonreactive,

16 similar to bromide, which is a commonly used conservative tracer (Davis et al., 1980; Bowman,

17 1984). When placed in geologic media that contain appreciable amounts of minerals (e.g., iron

18 oxides and kaolinite) or of organic matter with net positively charged surfaces that may attract

19 anions, the transport of FBAs (along with bromide) can be delayed, and FBAs can serve as

20 reactive tracers (Boggs et al., 1992; Benson and Bowman, 1994; Jaynes, 1994; Seaman, 1998).

21 In addition, during low-pH conditions, the non-inoized form of FBAs exhibits a considerable

22 sorption onto soil organic matter (Benson and Bowman, 1994; McCarthy et al., 2000).

23 A reliable analytical method that can distinguish several FBAs from one another is

24 crucial for multi-tracer studies. Such a method must be able to detect FBA tracers at low 
1 concentrations in the presence of other common anions (e.g., chloride, nitrate, and sulfate) that

2 preexist in soil and groundwaters. A robust analytical method is also needed for field tracer

3 experiments, which may collect hundreds of samples over a course of several years.

The most widely used method for FBA analysis was developed by Bowman (1984) that

5 uses high-performance liquid chromatography (HPLC) with UV detection after separation via a

6 strong anion exchange (SAX) column. This method has been used effectively in a number of

7 studies and can separate up to six FBAs simultaneously (Bowman and Gibbens, 1992; Benson

8 and Bowman, 1994). However, Bowman's method is subject to interference by several common

9 inorganic anions, including nitrate, iodide, bromide, and chloride. These anions are known to be

10 sensitive to UV detection and show significant absorption in the 195- to 215-nm range

11 (Stetzenbach and Thompson, 1983), a range that includes the 205- and 210-nm wavelengths

12 commonly used for FBA analyses. Analyses conducted with a SAX column are also complicated

13 by the rapid deterioration of the separation column in the presence of a low-pH buffered eluent

14 (TerBerg, 1993); this deterioration significantly limits the throughput of the analysis.

Another analytical method, reversed-phase HPLC, achieves separation by using the

16 different affinities of analytes and the stationary phase of the analytical column. When the

17 solution $\mathrm{pH}$ is below the $\mathrm{p} K_{\mathrm{a}}$ of the compound, ionizable compounds such as FBAs exist in

18 protonated form, are less soluble, and exhibit larger affinities.

Analytical procedures based on reversed-phase HPLC and UV detection have recently

20 been used to separate and quantify as many as 7 (Dahan and Ronen, 2001) or 10 FBA isomers

21 (Stringfellow et al., 2001) in a single run. The HPLC methods developed by Stringfellow et al.

22 (2001) simultaneously measure multiple FBAs in the presence of interfering compounds such as

23 nitrate and soluble organic matter. Resolution matrix tables have been constructed to assist the

24 selection of FBA tracers for use in studies where such interference may be present. In contrast, 
1 the reversed-phase HPLC method of Stetzenbach et al. (1982) requires a preconcentration of

2 aqueous samples and increases sensitivity by 3 orders of magnitude to allow low-level detection

3 of FBAs. However, this high sensitivity requires a greater sample volume by the same orders of

4 magnitude.

5 An ion chromatographic (IC) method with conductivity detection was used to separate

6 and analyze three FBAs (Pearson et al., 1992). However, this study found that even a low

7 concentration $(1 \mathrm{mg} / \mathrm{L})$ of chloride interfered with the chosen FBAs. Furthermore, the reported

8 detection limit was relatively high at $0.25 \mathrm{mg} / \mathrm{L}$.

9 Previous analytical methods for FBAs analysis have tested for the interference of

10 common inorganic anions, whether halides as tracers or preexisting groundwater constituents.

11 For example, Seaman (1998) reported a method that simultaneously analyzed bromide and four

12 FBAs, with an observed interference between bromide and 3,4-difluorobenzoic acid (DFBA).

13 However, we are not aware of any published research that specifically analyzes all of the

14 common anions in a single run. In addition, past researchers have traditionally used different

15 instruments and methods to analyze diffusivity tracers applied in a single experiment. For

16 example, bromide or iodide analyses have conventionally been performed via IC with a

17 conductivity detector or ion specific electrodes, while FBA analyses have been conducted by

18 HPLC with a UV absorbance detector (Turin et al., 2002; Reimus et al., 2003).

In this work, we present an IC method with conductivity detection that can

20 simultaneously separate and quantify multiple FBA isomers, all halides, and other common

21 groundwater anions. Our method applies recent developments in IC technologies, such as a

22 reagent-free eluent generator (to avoid the chemical usage and generation of wastes [e.g., acids

23 and organic solvents] required in other FBA analytical methods), an analytical column, and a

24 conductivity suppressor. All of these technologies contribute to a robust analytical method that is 
1 easy to operate, requires minimal sample pretreatment, and yields a superior detection limit. We

2 also describe disparate applications of this method in field and laboratory experiments that were

3 conducted to investigate the flow and transport in subsurface materials. Such investigations are

4 relevant to environmental characterization and remediation, or to a potential geologic repository

5 for high-level nuclear waste. These applications highlight the advantages of multi-tracer

6 experiments and analytical approaches.

7 MATERIALS AND METHODS

8 Reagents

$9 \quad$ We used reagent water with a resistance level of $18 \mathrm{M} \Omega$. The water was obtained from a

10 NANOpure Infinity Water Purification System (Barnstead International, Dubuque, IA). Our

11 study also used a total of 14 commercially available FBAs, which were purchased from Aldrich

12 Chemical Co. (Milwaukee, WI). The purity level of each FBA is listed in Table 1. All FBA

13 compounds were used without further purification. The other chemicals ( $\mathrm{LiF}, \mathrm{SrBr}_{2}$, CsI, and

$14 \mathrm{KIO}_{3}$ ) used in the laboratory column studies were also purchased from Aldrich Chemical Co.

15 Instrumentation for the analysis of inorganic anions

16 A Dionex (Dionex Corp., Sunnyvale, CA) ion chromatography DX-600 system was used

17 in this study to analyze FBAs and other anions. The system comprises a GP50 gradient pump, an

18 ED50A electrochemical detector in conductivity mode, and an AS50 autosampler with a thermal

19 compartment for temperature control. For separation purposes, an IonPac AG17 (4 × 50 mm; 4-

$20 \mathrm{~mm}$ inner diameter and 50-mm length) guard column was used in conjunction with an IonPac

21 AS17 $(4 \times 50 \mathrm{~mm})$ analytical column (both columns were maintained at $\left.35^{\circ} \mathrm{C}\right)$, along with an

22 ultra anion self-regenerating suppressor that operated at $248 \mathrm{~mA}$ in the recycled-water mode. An

23 EG50 eluent generator with an EGC-KOH cartridge and a CR-ATC (continuously regenerated

24 anion trap column) was employed to achieve a gradient separation by producing a varying 
1 concentration of $\mathrm{KOH}$ over the run at a flow rate of $1.0 \mathrm{~mL} / \mathrm{min}$. Using deionized water only, the

2 EG50 generates high-purity, carbonate-free $\mathrm{KOH}$ eluent that minimizes baseline shift, improves

3 retention time stability and resolution, and provides run-to-run reproducibility. An injection loop

4 size of $25 \mu \mathrm{L}$ was used for sample analyses. Finally, Dionex PeakNet 6.2 software was used for

5 system control, data collection and processing.

We developed a hydroxide gradient method to separate the multiple FBAs, halides, and

7 other common inorganic anions that existed in the groundwater. The timing of each step for a

8 hydroxide gradient run from a range of 2 to $60 \mathrm{mM} \mathrm{KOH}$ is presented in Table 2.

\section{$9 \quad$ Field experiments}

The experimental setup used in two liquid-release and tracer-transport studies in

11 unsaturated, fractured welded tuff at Yucca Mountain, Nevada, is described in detail in Salve et

12 al. (2002). Both studies were conducted within the Exploratory Studies Facility (ESF), an

13 excavated Yucca Mountain tunnel measuring $8 \mathrm{~km}$ long and $8 \mathrm{~m}$ in diameter at a depth of about

$14300 \mathrm{~m}$ below the top of the mountain.

In the first study, a series of tests was conducted by releasing tracer-laced water into two

16 isolated zones within a horizontal injection borehole drilled into the rock formation from the

17 tunnel. The low- and high-permeability zones were located at a distance of $0.75-1.05 \mathrm{~m}$ and $2.3-$

$182.6 \mathrm{~m}$, respectively, from the borehole collar. Seepage, if available, was collected in an

19 excavated slot about $1.6 \mathrm{~m}$ below the borehole, and the tracer concentration in the seepage

20 collection was analyzed. The tests conducted in the low-permeability zone used bromide and

21 three FBA tracers. Although no seepage occurred in this zone, information about the liquid-

22 intake rates, as well as formation wetting and drying, was obtained and discussed in Salve et al.

23 (2002). For the tests (called the fracture study in this paper) conducted in the high-permeability

24 zone, which likely has a well-connected fracture network, the first phase consisted of four liquid- 
1 release events with fluoride and four FBA tracers that were different from these FBAs used in

2 the low-permeability zone. One FBA was associated with each event, and each event had a

3 different release rate. The second phase investigated the transport behavior of the applied tracers

4 during flushing through four release events (and rates). No tracers were added in the second

5 phase. The tracer results under different release rates in the high-permeability zone were

6 presented and discussed in Hu et al. (2001).

7 The second study (called the fault study in this paper) investigated flow and transport in a

8 fault embedded in unsaturated tuff (Salve et al., in press). The experiment involved the direct

9 release of $\sim 82,000 \mathrm{~L}$ of water over a period of 17 months into a near-vertical fault under a

10 constant positive head (at $\sim 0.04 \mathrm{~m}$ ). Seven months after beginning water release along the fault,

11 when a stable flow regime had been established, a solution containing bromide and

12 pentafluorobenzoic acid (PFBA) were released along the fault for nine days. Afterwards, water

13 without tracers was released along the fault for another seven months. Seepage water was

14 continuously collected in a cavity excavated $\sim 20 \mathrm{~m}$ below the test bed and was analyzed for

15 chemical concentration.

16 Column experiments

17 Laboratory column experiments were conducted to demonstrate the usefulness of the IC 18 analytical method and to elucidate the transport behavior of the tracers (FBAs and halides) in

19 various geologic media in the United States (Table 3). These media were obtained within or near

20 several Department of Energy (DOE) complex sites, including the Savannah River Site (SRS) in

21 South Carolina; the Oak Ridge Reservation in Tennessee; the Hanford Site in Washington; the

22 Idaho National Engineering and Environmental Laboratory (INEEL) site in Idaho Falls, Idaho;

23 the Nevada Test Site (NTS) in Mercury, Nevada; a location in Santa Fe near Los Alamos

24 National Laboratory, New Mexico; and a site of Lawrence Livermore National Laboratory in 
1 Livermore, California. A sample of Wisconsin surface soil with a high amount of organic matter

2 was also included in the experiment. The wide variety of sample types provided an opportunity

3 to examine the influence of organic matter, clay mineralogy, soil $\mathrm{pH}$, and texture on the transport

4 behavior of inorganic anions. All properties presented in Table 3 were measured according to the

5 standard procedures in Methods of Soil Analysis (Klute, 1986; Sparks, 1996).

A glass column (2.5-cm inner diameter, 15.0-cm length; Kontes, Vineland, NJ) was

7 incrementally packed with the air-dried soil/sediment sample $(<2 \mathrm{~mm})$ to obtain uniform bulk

8 densities. The packed column was slowly wetted from the bottom to establish saturation, and

9 approximately 100 pore volumes of electrolyte solution ( $\left.5 \mathrm{mM} \mathrm{CaCl}_{2}\right)$ were pumped through the

10 column prior to the transport study. There were no visible air pockets after the column had been

11 saturated.

12 The apparatus and methods employed for the miscible displacement column studies were

13 similar to those used in previous experiments (Hu and Brusseau, 1995). One HPLC pump

14 (Model 301, Alltech Associates, Inc., Deerfield, IL) was connected to the column, and a three-

15 way switching valve was placed in-line to facilitate switching between solutions with and

16 without the tracer of interest. To investigate the simultaneous transport of four halides $\left(\mathrm{F}^{-}, \mathrm{Br}^{-}, \mathrm{I}^{-}\right.$

17 , and $\mathrm{IO}_{3}^{-}$) and four FBAs, we dissolved the following chemicals in the $5 \mathrm{mM} \mathrm{CaCl} 2$ electrolyte

18 solution: $\mathrm{LiF}, \mathrm{SrBr}_{2}$, CsI, $\mathrm{KIO}_{3}$, 2,6-DFBA, 3,4-DFBA, 3,4,5- trifluorobenzoic acid (TFBA), and

19 PFBA (each with an initial concentration of $1 \times 10^{-4} M$ ). The four FBAs were chosen because

20 they cover the $\mathrm{p} K_{\mathrm{a}}$ range of FBAs and can be analyzed in a single run. Two iodine species were

21 also used, as iodide and iodate have been reported to coexist in the environment (e.g., Yuita,

22 1994). In addition, a separate transport run of tritium (activity $33 \mathrm{kBq} / \mathrm{L}$ ) was carried out to

23 compare the transport behavior of tritium and the anionic tracers used in our column studies.

24 Column effluent fractions were collected with an automated fraction collector (Retriever 500, 
1 ISCO Inc., Lincoln, NE) for anion concentration determination by the IC method or for the

2 liquid scintillation counting of tritium.

3 RESULTS AND DISCUSSION

4 Separation of inorganic anions

$5 \quad$ Under a hydroxide gradient condition from a range of 2 to $60 \mathrm{mM} \mathrm{KOH}$, the retention

6 times for each FBA solution with a concentration of $10 \mathrm{mg} / \mathrm{L}$ are given in Table 1 . The wide

7 range in retention times, from 9.85 to $18.9 \mathrm{~min}$, for these $14 \mathrm{FBA}$ isomers demonstrates the

8 feasibility of good separation and accurate quantification of multiple FBAs. We also tested the

9 retention times of these FBAs under a gradient condition from a range of 2 to $40 \mathrm{mM} \mathrm{KOH}$, and

10 the resulting retention times exhibited an even wider range, from 9.94 to $21.3 \mathrm{~min}$, with the same

11 peak sequence. Depending upon a particular scenario and potential interferences, the gradient

12 range and steepness of change can be fine-tuned to achieve optimal separation.

13 We did not observe a correlation between the $\mathrm{p} K_{\mathrm{a}}$ values and the retention times of the

14 FBAs. In an alkaline eluent solution with a $\mathrm{pH}$ of $\sim 12$, each FBA is expected to exist in anionic

15 form. The different affinities (and hence retention times) between each FBA and the alkanol

16 quaternary ammonium functional group with low hydrophobicity that is packed in the analytical

17 IC column depend on the different polarities among the FBAs. A highly polarizable FBA anion,

18 which possesses an easily deformable electron cloud and exhibits a hydrophobic character, will

19 have a long retention time.

20 The IC method presented here provides a method detection limit (MDL) ranging from

$21 \quad 15.4$ to $29.4 \mu \mathrm{g} / \mathrm{L}$ for four FBAs tested with an injection volume of $25 \mu \mathrm{L}$, which corresponds to

22 a quantification limit ranging from of 0.38 to $0.74 \mathrm{ng}$ (Table 4). This detection limit was

23 obtained according to the procedure described in Method 300.0 from the U.S. Environmental

24 Protection Agency (1993). The MDL is determined by injecting seven replicates of reagent water 
1 spiked with an analyte at a concentration of 3 to 5 times the estimated instrument detection limit

2 (referred to as MDL solution). The MDL is then calculated as (t) $\times(\mathrm{SD})$ where $t$ is Student's $t$

3 value for a 99\% confidence level and a standard deviation (SD) estimate with $n-1$ degrees of

4 freedom ( $t=3.14$ for $n=7$ replicates). The retention time and peak area precision (expressed as

5 relative standard deviation, or RSD) were also determined from seven replicate injections (Table

6 4). The peak area RSD of less than $10 \%$ is obtained for the MDL solution of low (sub $\mathrm{mg} / \mathrm{L}$ )

7 concentration, while the peak area RSD for a solution spiked with about $1 \mathrm{mg} / \mathrm{L}$ analyte is less

8 than $2 \%$ (data not shown).

The MDL for FBAs is comparable to those of other anions obtained by the same

10 procedure (Table 4). In addition, the quantification limit for FBAs by this method is better than

11 those observed for FBAs by other methods. For example, Bowman (1984) tested four FBAs and

12 reported a limit in the range of 1.2 to $2.5 \mathrm{ng}$, while Stringfellow et al. (2001) observed a limit of

135 to 7 ng for 14 FBAs. Finally, Dahan and Ronen (2001) reported a detection limit of about

$140.5 \mathrm{mg} / \mathrm{L}$ for each of 13 FBAs studied but did not specify the injection volume that was used.

15 Based on the retention time of individual FBAs, halides, and other common anions, seven

16 FBAs (shown in boldface in Table 1) can be selected and potentially used in hydrological

17 studies. A representative chromatogram (Figure 1) shows the separation of these seven FBAs

18 and other common anions. Note that although 2,3,4,5-tetrafluorobenzoic acid (TeFBA) has a

19 retention time (15.7 min) close to that of phosphate (16.1 min), a typical groundwater sample has

20 only a trace concentration of phosphate. Therefore, 2,3,4,5-TeFBA could potentially be used as a

21 tracer in situations where the researchers have prior knowledge of the existing phosphate

22 concentration.

23 The use of a reagent-free eluent generator such as the EG-50 produces hydroxide eluent

24 at the desired concentration accurately and reproducibly. The carbonate-free hydroxide that is 
1 generated greatly reduces baseline shifts during a gradient run, improving signal-to-noise ratios.

2 The observed shift from 2 to $60 \mathrm{mM} \mathrm{KOH}$ is commonly less than $0.05 \mu \mathrm{S}$. In contrast, the

3 observed baseline shift under the same gradient is at least $1 \mu \mathrm{S}$ if using a bottle eluent delivery

$4 \quad$ system with an eluent prepared from hydroxide chemicals.

5 Demonstration of the IC method in field experiments

In this section, we demonstrate the utility of multiple FBA tracers in field applications

7 and the usefulness of our IC analytical method to determine the presence and concentration of

8 several FBAs, halide tracers, and other common anions in a single run. Figure 2 shows the

9 chromatograms of liquid samples collected in the fracture study discussed above. Figure 2a is an

10 IC chromatogram for a seepage sample collected after releasing dual tracers (PFBA and fluoride)

11 in the first tracer release event, and Figure $2 b$ is from a seepage sample collected after releasing

12 two additional FBA tracers (2,3,4-TFBA and 3,4-DFBA) from two ensuing tracer events. Figure

$132 \mathrm{~b}$ demonstrates the lingering presence of fluoride due to its sorption on the rock formation in

14 the flow pathways (Hu et al., 2001), as well as the gradual flushing of FBA tracers from the low-

15 permeability region. Note that all water (referred to as mine water) introduced into the ESF for

16 mining-related activities and scientific investigations (including these tracer tests) was

17 groundwater that was pumped from well J-13 (located near Yucca Mountain) and then spiked

18 with $20-30 \mathrm{mg} / \mathrm{L}$ of $\mathrm{LiBr}$. Because the $\mathrm{J}-13$ water contained about $2.5 \mathrm{mg} / \mathrm{L}$ of fluoride, a high

19 concentration (307 mg/L) of fluoride was added to the tracer solution. Furthermore, both the

20 released tracer solution and the collected seepage contained about $120 \mathrm{mg} / \mathrm{L}$ of bicarbonate,

21 which was converted into carbonate in the alkaline $\mathrm{pH}$ condition of the eluent during the IC run;

22 the resulting carbonate peak (not quantifiable) is shown in Figure 2. The peak retention time of

23 3,4-DFBA is close to that of phosphate, but phosphate is only occasionally present at a

24 concentration above the detection limit (as shown in Figure 2a). Out of more than 400 samples 
1 analyzed, only about 20 exhibited a small, yet detectable, peak that is presumably phosphate.

2 Furthermore, there was no pattern in the observed phosphate concentration for these 20 samples.

3 Therefore, the detection and quantification of 3,4-DFBA were not compromised.

Figure 3 shows the chromatograms for the liquid samples collected in the fault study.

5 During this study, a long-term tracer test was conducted to investigate the matrix diffusion in

6 unsaturated tuff with an embedded fault (Salve et al., in press). A dual tracer of PFBA and

7 bromide was applied, and the anionic constituents in the released tracer solution are shown in a

8 chromatogram (Figure 3a). Figure 3b shows the chromatogram for a representative seepage

9 sample collected about $20 \mathrm{~m}$ below the release point. Figure 3 demonstrates the ability of the IC

10 analytical method to separate and quantify diffusivity tracers (e.g., bromide and PFBA), as well

11 as other common anions, in a single run. Results from these diffusivity tracers indicate

12 significant effects of matrix diffusion on transport through a fault within unsaturated tuff (Salve

13 et al., in press).

14 The simultaneous measurement of tracers and other anions has several advantages. First,

15 it is economical because it requires just one instrument. The procedure also provides a quick

16 turnaround time, allowing timely modification of test plans and experimental implementation. In

17 addition, simultaneous measurement provides the researchers with the concentration of all major

18 anions (except bicarbonate) present in a water sample. This concentration can then be used to

19 conduct the charge balance calculation that is helpful in data processing and interpretation. Last

20 but not least, the simultaneous measurement of major anions (tracers and others) enhances the

21 interpretation of experimental results.

22 In the fault tracer study, for example, the two types of released waters (mine water and

23 tracer solution) have similar concentrations of chloride, nitrate, and sulfate (Table 5). The

24 seepage solution collected after releasing mine water, however, exhibits concentrations that are 
1 about 3 times higher for these anions, presumably from solution-rock interactions as the solution

2 passed through the rock formation. The seepage solution obtained after applying the tracer

3 solution still shows high, although a bit decreased, concentrations of these anions. The reduced

4 concentrations reflect the continuing dilution of the antecedent salts in the formation fluid as

5 well as the anion exchange process occurring from the high concentration of bromide applied.

6 This type of data could be used in transport modeling studies that incorporate water-rock

7 interaction and mechanistic anion exchange processes.

8 Laboratory column experiments

9 Laboratory tests further illustrate the usefulness of the IC analytical method in

10 investigating the simultaneous transport of multiple tracers in a column packed with a geologic

11 medium. A representative chromatogram from the Hanford column experiment is shown in

12 Figure 4a to demonstrate the separation and quantification of multiple anionic tracers. For the

13 samples obtained from Hanford, INEEL, NTS, and Livermore, all four tested FBAs exhibited

14 identical breakthrough curves (with symmetrical behavior and negligible tailing) and

15 conservative (not retarded) transport—-the same transport behavior as that of tritium and

16 bromide. A representative breakthrough curve for the Hanford sediment is shown in Figure $4 \mathrm{~b}$.

17 Such conservative behavior is expected in geologic media with predominantly negatively

18 charged surfaces and nonacidic $\mathrm{pH}$ conditions, which is consistent with other reports (e.g.,

19 Bowman and Gibbens, 1992; Turin et al., 2002).

20 In highly weathered sediments from the southeastern United States (such as the Oak

21 Ridge and SRS samples used in this study), however, some or all of the FBAs that were studied

22 exhibited retarded transport, as shown for the SRS subsurface sample in Figure 5a. These

23 samples contained appreciable amounts of minerals, such as kaolinite and iron (Fe) oxides,

24 which possess positively charged surfaces and contribute to anion sorption. Several reports have 
1 documented the reactive behavior of FBA tracers in similar media (Boggs and Adams, 1992;

2 Seaman, 1998).

Selective extraction was used to target the different fractions of Fe in the sample. For

4 example, citrate-bicarbonate-dithionite (CBD) extractable Fe contains crystalline iron oxide

5 minerals such as hematite, goethite, lepidocrocite, and ferrihydrite, while ammonium oxalate

6 extraction targets noncrystalline Fe oxides, including ferrihydrite and ferrihydrite-like minerals

7 (Loeppert and Inskeep, 1996). Both the SRS subsurface and Oak Ridge media had a relatively

8 high crystalline Fe oxide content, along with Wisconsin soil and Livermore alluvium (Table 3).

9 As determined by x-ray diffraction, the clay mineralogy of the SRS subsurface sample consisted

10 mainly of kaolinite, goethite, and hydroxy-interlayered vermiculite (Seaman, 1998). The anion

11 sorption capacity of the geologic media was also reflected in the measured anion exchange

12 capacity (AEC). The AEC values for the media are listed in Table 3, which shows an AEC value

13 as high as $4.04 \mathrm{meq} / 100 \mathrm{~g}$ sample for the SRS subsurface medium. The measured AEC value for

14 Oak Ridge sediment was not as large as the AEC values for other media, such as the Livermore

15 alluvium that did not exhibit noticeable sorption of FBAs. The sorption of FBAs in the Oak

16 Ridge medium was probably related to the medium's low $\mathrm{pH}$ value. The measured $\mathrm{pH}$ in the

17 effluent samples for the Oak Ridge column was $4.12 \pm 0.02(n=41)$, which is very close to the

$18 \mathrm{p} K_{\mathrm{a}}$ values of FBAs, compared with the measured $\mathrm{pH}$ of the effluent samples for the Livermore

19 column was $6.69 \pm 0.23(n=30)$. At Oak Ridge sediment with low $\mathrm{pH}$ values, an appreciable

20 proportion of FBA exists in non-polar non-ionized, which can then be sorbed onto organic

21 matter and clay fraction of the mineral phase. At pH value of 4.12 for Oak Ridge column, the

22 proportion of non-ionized form is 33.9, 20.8, 5.1, and 3.8\% for 3,4-DFBA, 3,4,5-TFBA, 2,6-

23 DFBA, and PFBA, respectively, as calculated by the Henderson-Hasselbach equation (McCarthy 
1 et al., 2000). At the $\mathrm{pH}$ value of 6.69 for Livermore column, the proportion for all these four

2 FBAs is less than $0.1 \%$.

We also examined the transport behavior of FBAs in two samples with a high organic

4 matter content, 2.3\% for Owngate soil and 8.7\% for Wisconsin soil, respectively. The

5 breakthrough curve results indicate some sorption of FBAs with these soils (a higher retardation

6 for Wisconsin soil than Owngate soil), indicating the interaction of the FBAs with the organic

7 matter in the soil; retardation for the Wisconsin soil is presented in Figure 5b. In laboratory

8 experiments using two soil samples that had a similar organic matter content to the Wisconsin

9 soil sample used here, Jaynes (1993) reported a slight sorption of 3,4-DFBA and 3,5-DFBA and

10 conservative transport of PFBA and 2,6-DFBA.

11 The retardation factor $(R)$ and mass recovery, calculated by moment analyses of the

12 breakthrough curves, are listed in Table 6. The $R$ values of FBAs in the SRS subsurface, Oak

13 Ridge sediment, and Wisconsin soil exhibited a sequence that follows the $\mathrm{p} K_{\mathrm{a}}$ values of the four

14 tested FBAs (3,4-DFBA > 3,4,5-TFBA > 2,6-DFBA > PFBA): the smaller the $\mathrm{p} K_{\mathrm{a}}$ value, the

15 smaller the $R$ value. At a certain $\mathrm{pH}$, a compound with a smaller $\mathrm{p} K_{\mathrm{a}}$ value will have a smaller

16 proportion in the protonated form that can be electrostatically sorbed onto anion sorption sites.

17 The observed sorption of FBAs was likely caused a combination of the electrostatic attraction for

18 proportion of anionic FBA form onto positively charged sites (e.g., for the SRS and Wisconsin

19 media), and partitioning of organic FBAs in organic matter (e.g., Oak Ridge medium and

20 Wisconsin soil).

21 To a lesser extent, the sorption of bromide also occurred in these media. Nevertheless,

22 the observed mass recovery for these tracers in these three media was about 100\% (Table 6),

23 indicating the absence of solute-media interactions that lead to mass loss (i.e., irreversible

24 sorption or degradation). In the SRS subsurface and Wisconsin soil samples, PFBA exhibited a 
1 similar retardation to that of bromide. PFBA also showed the smallest retardation among the

2 tested FBAs. Thus, if only one FBA isomer is needed as a hydrologic tracer, PFBA is the best

3 choice, next to bromide, because of PFBA's limited potential for sorption and its resistance to

4 degradation. (PFBA's resistance to degradation can be attributed to its possessing the highest

5 number of fluorine atoms in the benzene ring.) Our results show that the potential reactive

6 transport of anionic tracers, such as bromide and FBAs, must be taken into account when

7 designing and interpreting tracer tests in hydrologic studies.

8 Tritium has been considered an ideal water tracer (Davis et al., 1980). However, a slight

9 retardation of tritium (with a retardation factor larger than 1) was observed in the columns

10 packed with Wisconsin soil and Oak Ridge sediment. Tritium sorptions of similar magnitude

11 have been reported in numerous publications (e.g., Wierenga et al., 1975; van Genuchten and

12 Wierenga, 1977; Gaber et al., 1995; Hu and Brusseau, 1996). For example, the retardation factor

13 for tritium was measured to be 1.17 in an aggregated tropical soil (Seyfried and Rao, 1987) and

141.2 in a column packed with glass beads and porous kaolinite spheres (Hu and Brusseau, 1996).

15 The interaction of tritium with solid surfaces has been postulated to occur via hydroxyl exchange

16 with clay lattice hydroxyls (Stewart and Baker, 1973). This process is more pronounced in

17 kaolinite minerals that have available hydroxyl groups at platelet surfaces.

18 In reducing environments, aqueous iodine usually occurs as the mobile iodide anion $\left(\mathrm{I}^{-}\right)$.

19 Under more oxidizing conditions, iodine may be present as the more reactive iodate anion $\left(\mathrm{IO}_{3}{ }^{-}\right)$,

20 which exhibits retarded transport because iodate interacts with clays and organic matter (Couture

21 and Seitz, 1983; Sheppard and Thibault, 1992; Yoshida et al., 1992). The disparate sorption

22 behavior of iodide and iodate was confirmed in our study, which consistently showed the

23 sorption of iodate to be much higher and mass recovery to be much lower than for iodide. Even

24 in the Hanford sediment, a noticeable sorption of iodate took place, with an observed retardation 
1 factor of 1.4. Care should be exercised with regard to the potential conversion of iodine species

2 under different geochemical conditions — even when the iodide form is applied during a tracer

3 study — because the conversion of iodide to iodate or elemental iodine will confound the

4 interpretation of a tracer study's results.

5 Compared to FBA and other halide anions, a significant sorption of fluoride has been

6 commonly reported with minerals such as hydrous iron oxide, montmorillonite, and calcite

7 (Bower and Hatcher, 1967; Farrah and Pickering, 1986; Bar-Yosef et al., 1988). We observed a

8 significantly high sorption and a low mass recovery of fluoride in all eight media that were

9 examined. Thus, fluoride is the least appropriate halide for use as a hydrologic tracer.

\section{CONCLUSION}

11 To further exploit the applications of FBAs and halides as hydrologic tracers, an IC

12 analytical method was developed. The method, which can simultaneously separate and quantify

13 up to seven FBAs and halides from other common groundwater constituents in a single run, was

14 shown to be robust with a high sensitivity. The usefulness of the developed analytical method

15 was shown in both field and laboratory tracer experiments. In field tests examining transport and

16 matrix-diffusion behavior in unsaturated tuff that feature fractures and a fault, the IC analytical

17 method offered multiple advantages. Its single-run capability made the method efficient and

18 cost-effective. The method also increased confidence in sample analyses from charge balance

19 calculations and provided anion results for a database that could be used in water-rock

20 interaction modeling. Laboratory tracer experiments with eight geologic media across the United

21 States, which were mostly related to DOE facilities with prevalent groundwater contamination,

22 further demonstrated potential applications of the IC analytical method.

23 Our studies showed that the transport behavior of FBAs, as well as bromide, was not

24 ubiquitously conservative. The delayed transport of these tracers is related to media 
1 characteristics, such as the presence of organic matter, $\mathrm{pH}$, iron oxide content, and clay

2 mineralogy. Iodine is one of commonly used hydrologic tracers. As a redox-sensitive element,

3 iodine can exist in various forms, including iodide and iodate. Of the two forms, iodate was

4 found to have a greater tendency for retention in geologic media. Our results also demonstrate

5 the value of evaluating the transport behavior of potential FBA and halide tracers under relevant

6 geochemical conditions before embarking on ambitious, large-scale field tracer experiments. 


\section{REFERENCES}

2 Bar-Yosef B, Afik I, Rosenberg R. 1988. Fluoride sorption by montmorillonite and kaolinite.

3 Soil Science 145(3): 194-200.

4 Benson CF, Bowman RS. 1994. Tri- and tetrafluorobenzoates as nonreactive tracers in soil and 5 groundwater. Soil Science Society of America Journal 58: 1123-1129.

6 Boggs JM, Adams EE. 1992. Field study in a heterogeneous aquifer. 4. Investigation of $7 \quad$ adsorption and sampling bias. Water Resources Research 28: 3325-3336.

8 Boggs JM, Young SC, Beard LM, Gelhar LW, Rehfeldt KR, Adams EE. 1992. Field study of 9 dispersion in a heterogeneous aquifer. 1. Overview and site description. Water Resources $10 \quad$ Research 28: 3281-3291.

11 Bower CA, Hatcher JT. 1967. Adsorption of fluoride by soils and minerals. Soil Science 103(3): $12 \quad 151-154$.

13 Bowman RS. 1984. Analysis of soil extracts for inorganic and organic tracer anions via high14 performance liquid chromatography. Journal of Chromatography 285: 467-477.

15 Bowman RS, and Gibbens JF. 1992. Difluorobenzoates as nonreactive tracers in soil and 16 groundwater. Ground Water 30: 8-14.

17 Callahan TJ, Reimus PW, Bowman RS, Haga MJ. 2000. Using multiple experimental methods to 18 determine fracture/matrix interactions and dispersion of nonreactive solutes in saturated 19 volcanic tuff. Water Resources Research 36(12): 3547-3558.

20 Couture RA, Seitz MG. 1983. Sorption of anions of iodine by iron oxides and kaolinite. Nuclear 21 and Chemical Waste Management 4: 301-306.

22 Dahan O, Nativ R. Adar EM, Berkowitz B, Ronen Z. 1999. Field observation of flow in a 23 fracture intersecting unsaturated chalk. Water Resources Research 35(11): 3315-3326. 
1 Dahan O, Ronen Z. 2001. Analytical procedures for simultaneous use of seven fluorobenzoates

2 in multitracer tests. Ground Water 39(3): 366-370.

3 Davis SN, Thompson GM, Bentley HW, Stiles G. 1980. Groundwater tracers - Short review.

$4 \quad$ Ground Water 18(1): 14-23.

5 Farrah H, Picking WF. 1986. Interaction of dilute fluoride solutions with hydrous iron oxides.

$6 \quad$ Australian Journal of Soil Research 24: 201-208.

7 Gaber HM, Inskeep WP, Comfort SD, Wraith JM. 1995. Non-equilibrium transport of atrazine

8 through large intact soil cores. Soil Science Society of America Journal 59: 60-67.

9 Hu Q, Brusseau ML. 1995. Effect of solute size on transport in structured porous media. Water

$10 \quad$ Resources Research 31: 1637-1646.

11 Hu Q, Brusseau ML. 1996. Transport of rate-limited sorbing solutes in an aggregated porous

12 medium: A multiprocess non-ideality approach. Journal of Contaminant Hydrology 24: 53-

$13 \quad 73$.

14 Hu Q, Salve R, Stringfellow WT, Wang JSY. 2001. Field tracer transport tests in unsaturated

15 fractured tuffs. Journal of Contaminant Hydrology 51(1-2): 1-12.

16 Hu Q, Kneafsey TK, Trautz RC, Wang JSY. 2002. Tracer penetration into welded tuff matrix

17 from flowing fractures. Vadose Zone Journal 1: 102-112.

18 Hydro Geo Chem, Inc. 1986. Two-well recirculation tracer tests at the H-2 hydropad, waste

19 isolation plant (WIPP), southeastern New Mexico. SAND86-7092. Sandia National

20 Laboratories, Albuquerque, NM.

21 Jaynes DB. 1994. Evaluation of fluorobenzoate tracers in surface soils. Ground Water 32: 532

22538.

23 Klute A (ed). 1986. Methods of Soil Analysis: Physical and Mineralogical Methods. Part 1.

24 Second Edition. Soil Science Society of America: Madison, WI. 
1 Loeppert RL, Inskeep WP. 1996. Iron. In Methods of Soil Analysis: Chemical Methods. Part 3,

2 Sparks, DL (ed). Soil Science Society of America: Madison, WI, 639-664.

3 Mayes MA, Jardine PM, Mehlhorn TL, Bjornstad BN, Ladd T, Zachara JM. 2003. Transport of

4 multiple tracers in variably saturated humid region structured soils and semi-arid region

5 laminated sediments. Journal of Hydrology 275(3-4): 141-161.

6 McCarthy JF, Howard KM, McKay LD. 2000. Effect of pH on sorption and transport of

7 fluorobenzoic acid ground water tracers. Journal of Environmental Quality 29(6): 180681813

9 Nelson NT, Hu Q, Brusseau ML. 2003. Characterizing the contribution of diffusive mass transfer 10 to solute transport at the laboratory and field scales. Journal of Hydrology 276: 275-286.

11 Pearson RJ, Comfort SD, Inskeep WP. 1992. Analysis of florobenzoate tracers by ion

12 chromatography. Soil Science Society of America Journal 56: 1794-1796.

13 Pearson RJ, Inskeep WP, Wraith JM, Comfort SD, Gaber HM. 1996. Observed and simulated

14 solute transport under varying water regimes: I. Bromide and pentafluorobenzoic acid.

15 Journal of Environmental Quality 25: 646-653.

16 Reimus PW, Haga MJ, Adams AI, Callahan TJ, Turin HJ, Counce DA. 2003. Testing and

17 parameterizing a conceptual solute transport model in saturated fractured tuff using sorbing

18 and nonsorbing tracers in cross-hole tracer tests. Journal of Contaminant Hydrology 62-3:

$19 \quad 613-636$.

20 Salve R, Wang JSY, Doughty C. 2002. Liquid-release tests in unsaturated fractured welded tuffs:

21 I. Field investigations. Journal of Hydrology 256(1-2): 60-79.

22 Salve R, Liu HH, Cook P, Czarnomski A, Hu Q, Hudson D. 2004 (in press). Unsaturated flow

23 and transport through a fault embedded in fractured welded tuff. Water Resources Research. 
1 Seaman JC. 1998. Retardation of fluorobenzoate tracers in highly weathered soil and

2 groundwater systems. Soil Science Society of America Journal 62: 354-361.

3 Seyfried MS, Rao PSC. 1987. Solute transport in undisturbed columns of an aggregated tropical

4 soil: Preferential flow effects. Soil Science Society of America Journal 51: 1434-1444.

5 Sheppard M. Thibault DH. 1992. Chemical behavior of iodine in organic and mineral soils.

$6 \quad$ Applied Geochemistry 7: 265-272.

7 Sparks DL (ed). 1996. Methods of Soil Analysis: Chemical Methods. Part 3. Soil Science Society

8 of America: Madison, WI.

9 Stetzenbach KJ, Jensen SL, Thompson GM. 1982. Trace enrichment of fluorinated organic acids

10 used as groundwater tracers by liquid chromatography. Environmental Science and

11 Technology 16: 250-254.

12 Stetzenbach KJ, Thompson GM. 1983. A new method for simultaneous measurement of $\mathrm{Cl}, \mathrm{Br}$,

$13 \mathrm{NO}_{3}$, SCN, and I at sub-ppm levels in ground water. Ground Water 21(1): 36-41.

14 Stewart GL, Baker JH. 1973. Factors influencing the use of tritium as a tracer of soil water.

15 Agronomy Abstracts. American Society of Agronomy: Madison, WI, 79.

16 Stringfellow WT, Hu Q, TerBerg R., Castro G. 2001. Analyzing multiple fluorobenzoate tracers

17 in the presence of interfering compounds. LBNL-46976. Lawrence Berkeley National

18 Laboratory, Berkeley, CA.

19 TerBerg R. 1993. Multiple tracer breakthrough resolution at a pumping well. Masters thesis,

20 New Mexico Institute of Mining and Technology, Socorro, NM.

21 Turin HJ, Groffman AR, Wolfsberg LE, Roach JL, Strietelmeier BA. 2002. Tracer and

22 radionuclide sorption to vitric tuffs of Busted Butte, Nevada. Applied Geochemistry 17(6):

$23 \quad 825-836$. 
1 U.S. Environmental Protection Agency (EPA) Method 300.0. 1993. The determination of

2 inorganic anions in water by ion chromatography. Cincinnati, $\mathrm{OH}$.

3 van Genuchten MT, Wierenga PJ. 1977. Mass transfer studies in sorbing porous media: 2.

4 Experimental evaluation with tritium $\left({ }^{3} \mathrm{H}_{2} \mathrm{O}\right)$. Soil Science Society of America Journal 41:

$5 \quad 272-278$.

6 Wierenga PJ, van Genuchten MT, Boyle FW. 1975. Transfer of boron and tritiated water through

7 sandstone. Journal of Environmental Quality 4: 83-87.

8 Yoshida S, Muramatsu Y, Uchida S. 1992. Studies on the sorption of $\mathrm{I}^{-}$(iodide) and $\mathrm{IO}_{3}{ }^{-}$

9 (iodate) onto andosols. Water, Air, and Soil Pollution 63: 321-329.

10 Yuita K. 1994. Overview and dynamics of iodine and bromine in the environment. 1. Dynamics

11 of iodine and bromine in soil-plant system. JARQ—Japan Agricultural Research Quarterly

12 28: 90-99.

13 


\section{ACKNOWLEDGEMENTS}

2 This work was supported by the Laboratory Directed Research and Development

3 program at Lawrence Livermore National Laboratory (LLNL). We gratefully acknowledge John

4 Seaman of Savannah River Ecology Laboratory, David Watson of Oak Ridge National

5 Laboratory, and John Zachara of Pacific Northwest National Laboratory for providing the

6 samples used in the laboratory column experiments described in this paper. William Austin of

7 Oregon State University provided assistance in analyzing some properties of the samples. We

8 also thank This work was performed under the auspices of the U.S. Department of Energy by the

9 University of California, Lawrence Livermore National Laboratory under Contract W-7405-Eng-

10 48. The authors also thank Emmeline Chen of LLNL for many helpful comments. 


\section{Figure Legends}

Figure 1 IC chromatogram of inorganic anions. All FBA isomers have a concentration of $5 \mathrm{mg} / \mathrm{L}$. Other anions have the following concentrations: fluoride, $3.6 \mathrm{mg} / \mathrm{L}$; chloride, $7.2 \mathrm{mg} / \mathrm{L}$; bromide, nitrate, and sulfate, $14.3 \mathrm{mg} / \mathrm{L}$; phosphate, $21.4 \mathrm{mg} / \mathrm{L}$.

Figure 2 IC chromatograms of inorganic anions for seepage samples collected during two phases of fracture tracer studies at Yucca Mountain, Nevada.

Figure 3 IC chromatograms of inorganic anions for samples collected from a fault tracer study at Yucca Mountain, Nevada: (a) released tracer solution; (b) collected seepage solution.

Figure 4 Transport of tracers in a column homogeneously packed with Hanford sediment. (a) IC chromatograms of inorganic anions for a representative column effluent sample. Note that a gradient condition over a range of 2 to $40 \mathrm{mM} \mathrm{KOH}$ was employed and that molybdate was applied as a tracer. (b) Breakthrough curves of tracers (column residence times for tritium and anionic tracers were 1.94 hours and 1.47 hours, respectively).

Figure 5 Breakthrough curves of tritium and anionic tracers in a column homogeneously packed with (a) Savannah River Site subsurface sediment (column residence times for tritium and anionic tracers were 1.36 hours and 1.70 hours, respectively) and (b) Wisconsin soil (column residence times for tritium and anionic tracers were 4.08 hours and 1.87 hours, respectively). 
Table 1. Isomers of FBAs examined in this study

\begin{tabular}{lccc}
\hline \multicolumn{1}{c}{ FBA $^{\mathrm{a}}$} & $\mathrm{p} K_{\mathrm{a}}^{\mathrm{b}}$ & Purity & $\begin{array}{c}\text { Retention time } \\
(\mathrm{min})\end{array}$ \\
\hline 2,3-DFBA & 3.29 & $98 \%$ & 11.7 \\
2,4-DFBA & 3.58 & $98 \%$ & 11.4 \\
2,5-DFBA & 3.30 & $\mathbf{9 8 \%}$ & $\mathbf{1 1 . 3}$ \\
2,6-DFBA & $\mathbf{2 . 8 5}$ & $\mathbf{9 8 \%}$ & $\mathbf{9 . 8 5}$ \\
3,4-DFBA & 3.83 & $98 \%$ & 17.0 \\
3,5-DFBA & 3.59 & $97 \%$ & 15.4 \\
2,3,4-TFBA & 3.30 & $98 \%$ & 13.8 \\
2,3,6-TFBA & 2.82 & $99 \%$ & 11.2 \\
2,4,5-TFBA & 3.28 & $\mathbf{9 9 \%}$ & $\mathbf{1 3 . 0}$ \\
2,4,6-TFBA & 2.83 & $98 \%$ & 10.5 \\
3,4,5 TFBA & $\mathbf{3 . 5 4}$ & $\mathbf{9 8 \%}$ & $\mathbf{1 8 . 9}$ \\
2,3,4,5-TeFBA & $\mathbf{3 . 0 8}$ & $\mathbf{9 9 \%}$ & $\mathbf{1 5 . 7}$ \\
2,3,5,6-TeFBA & $\mathbf{2 . 7 1}$ & $\mathbf{9 9 \%}$ & $\mathbf{1 2 . 5}$ \\
PFBA & $\mathbf{2 . 7 2}$ & $\mathbf{9 9 \%}$ & $\mathbf{1 4 . 7}$ \\
\hline
\end{tabular}

âDFA: difluorobenzoic acid; TFBA: trifluorobenzoic acid; TeFBA: tetrafluorobenzoic acid;

PFBA: pentafluorobenzoic acid.

${ }^{\mathrm{b}}$ Values of $\mathrm{p} K_{\mathrm{a}}$ (negative log acid dissociation constant) are from Benson and Bowman (1994).

${ }^{\mathrm{c}}$ Obtained from a $10 \mathrm{mg} / \mathrm{L}$ of FBA solution in the reagent water. 
Table 2. Hydroxide gradient separation of inorganic anions using EG50

\begin{tabular}{ccl}
\hline Time (min) & $\begin{array}{c}\text { Eluent conc. } \\
(\mathrm{m} M)\end{array}$ & \multicolumn{1}{c}{ Comments } \\
\hline $\begin{array}{c}\text { Equilibration } \\
-2\end{array}$ & 2 & $\begin{array}{l}\text { Preconditioning before sample analysis } \\
\text { Sample injection at time zero }\end{array}$ \\
4 & 2 & Isocratic analysis for fluoride \\
6 & 10 & Linear gradient \\
12 & 30 & Separation of bromide from nitrate; linear gradient \\
16 & 45 & Linear gradient \\
20 & 60 & Linear gradient \\
20.1 & 2 & Returns to initial condition for next analysis \\
\hline
\end{tabular}


Table 3. Information and properties of samples used in the column experiments ${ }^{\mathrm{a}}$

\begin{tabular}{|c|c|c|c|c|c|c|c|c|c|}
\hline \multicolumn{2}{|l|}{ Sample } & $\begin{array}{l}\text { Hanford } \\
\text { sediment }\end{array}$ & $\begin{array}{c}\text { LLNL } \\
\text { alluvium }\end{array}$ & NTS tuff & $\begin{array}{l}\text { INEEL } \\
\text { basalt }\end{array}$ & $\begin{array}{c}\begin{array}{c}\text { Owngate } \\
\text { soil }\end{array} \\
\end{array}$ & $\begin{array}{c}\text { Oak Ridge } \\
\text { sediment }\end{array}$ & $\begin{array}{c}\text { SRS } \\
\text { subsurface }\end{array}$ & $\begin{array}{l}\text { Wisconsin } \\
\text { soil }\end{array}$ \\
\hline \multicolumn{2}{|l|}{ Description } & $\begin{array}{l}\text { Composite } \\
\text { of core } \\
\text { samples 9- } \\
12 \text { m depth } \\
\text { below } \\
\text { surface }\end{array}$ & $\begin{array}{l}0.7 \mathrm{~m} \\
\text { below } \\
\text { surface }\end{array}$ & $\begin{array}{l}\text { Crushed } \\
\text { tuff } \\
\sim 300 \mathrm{~m} \\
\text { below } \\
\text { surface }\end{array}$ & $\begin{array}{l}\text { Crushed } \\
\text { basalt core } \\
0.3 \mathrm{~m} \\
\text { below } \\
\text { surface }\end{array}$ & $\begin{array}{l}\text { Surface } \\
\text { soil }\end{array}$ & $\begin{array}{l}\text { Composite } \\
\text { of core } \\
\text { samples 2- } \\
3 \text { m depth } \\
\text { below } \\
\text { surface }\end{array}$ & $\begin{array}{l}\text { Composite } \\
\text { of sediment } \\
12 \mathrm{~m} \text { below } \\
\text { surface }\end{array}$ & $\begin{array}{l}\text { Surface } \\
\text { soil }\end{array}$ \\
\hline \multicolumn{2}{|l|}{ Location } & $\begin{array}{l}\text { Richland, } \\
\text { WA }\end{array}$ & $\begin{array}{l}\text { Livermore, } \\
\text { CA }\end{array}$ & $\begin{array}{l}\text { Mercury, } \\
\text { NV }\end{array}$ & $\begin{array}{l}\text { Idaho } \\
\text { Falls, ID }\end{array}$ & $\begin{array}{l}\text { Santa Fe, } \\
\text { NM }\end{array}$ & $\begin{array}{l}\text { Oak Ridge, } \\
\text { TN }\end{array}$ & Aiken, SC & $\begin{array}{l}\text { Plover, } \\
\text { WI }\end{array}$ \\
\hline $\mathrm{pH}$ & $\begin{array}{l}\text { (standard } \\
\text { unit) }\end{array}$ & 8.5 & 8.0 & 8.9 & 8.5 & 7.7 & 4.5 & 5.4 & 5.9 \\
\hline $\begin{array}{l}\text { Organic } \\
\text { matter }\end{array}$ & $(\%)$ & 0.06 & 0.03 & 0.14 & 0.04 & 2.30 & 0.12 & 0.07 & 8.70 \\
\hline $\begin{array}{l}\text { Particle } \\
\text { size }\end{array}$ & clay (\%) & n.a. & n.a. & n.a. & n.a. & n.a. & 21.4 & 19.8 & 12.0 \\
\hline CEC & (meq/100 g) & 7.37 & 26.32 & 4.54 & 1.67 & 15.08 & 9.41 & 1.78 & 14.08 \\
\hline $\mathrm{AEC}$ & (meq/100 g) & 0.007 & 0.35 & 0.18 & 0.13 & 0.008 & 0.12 & 4.04 & 0.009 \\
\hline Iron-CBD & (g Fe/kg) & 3.26 & 9.78 & 1.48 & 3.12 & 3.82 & 10.83 & 15.92 & 10.08 \\
\hline $\begin{array}{l}\text { Iron- } \\
\text { oxalate }\end{array}$ & (g Fe/kg) & 0.94 & 0.94 & 0.12 & 12.90 & 0.21 & 1.84 & 0.20 & 5.86 \\
\hline
\end{tabular}

${ }^{\mathrm{a} C E C}$ : cation exchange capacity; AEC: anion exchange capacity; CBD: citrate-bicarbonate-dithionite; oxalate: ammonium oxalate.

Sample pH value was measured in a 1:1 soil/deionized water suspension. n.a.: not available (waiting for the analysis results). 
Table 4. Parameters obtained by the IC method for halide tracers and other anions ${ }^{\mathrm{a}}$

\begin{tabular}{ccccc}
\hline Anion & $\begin{array}{c}\text { Method } \\
\text { detection } \\
\text { limit } \\
\text { (ug/L) }\end{array}$ & $\begin{array}{c}\text { Retentio } \\
\text { n time } \\
\text { (min) }\end{array}$ & $\begin{array}{c}\text { Retention } \\
\text { time } \\
\text { precision } \\
\text { (RSD) }\end{array}$ & $\begin{array}{c}\text { Area } \\
\text { precision } \\
\text { (RSD) }\end{array}$ \\
\hline Fluoride & 3.84 & 3.40 & $0.13 \%$ & $5.2 \%$ \\
Iodate & 21.7 & 3.76 & $0.11 \%$ & $8.8 \%$ \\
Chloride & 11.1 & 7.95 & $0.17 \%$ & $4.6 \%$ \\
Nitrite & 26.1 & 8.54 & $0.10 \%$ & $6.7 \%$ \\
2,6-DFBA & 23.0 & 9.51 & $0.09 \%$ & $7.9 \%$ \\
Bromide & 17.7 & 9.82 & $0.06 \%$ & $6.3 \%$ \\
Nitrate & 6.60 & 10.68 & $0.15 \%$ & $2.7 \%$ \\
Sulfate & 41.6 & 13.46 & $0.15 \%$ & $1.7 \%$ \\
PFBA & 29.4 & 14.16 & $0.24 \%$ & $8.8 \%$ \\
3,4-DFBA & 17.6 & 15.37 & $0.37 \%$ & $6.3 \%$ \\
Phosphate & 39.4 & 16.07 & $0.03 \%$ & $6.1 \%$ \\
Iodide & 19.9 & 16.76 & $0.12 \%$ & $9.4 \%$ \\
TFBA & 15.4 & 18.57 & $0.09 \%$ & $4.7 \%$ \\
\hline
\end{tabular}

${ }^{\mathrm{a}}$ All with an injection volume of $25 \mu \mathrm{L}$. 
Table 5. Change of anion concentration during a tracer test

\begin{tabular}{|c|c|c|c|c|c|c|c|c|}
\hline \multirow[b]{2}{*}{ Anion } & $\begin{array}{r}\text { Minc } \\
\text { (35 mea } \\
\text { Conce } \\
\text { (m }\end{array}$ & $\begin{array}{l}\text { water } \\
\text { arements) } \\
\text { tration } \\
\text { /L) }\end{array}$ & $\begin{array}{r}\text { Tracer } \\
\text { (6 meas } \\
\text { Conce } \\
\text { (m }\end{array}$ & $\begin{array}{l}\text { solution } \\
\text { rements) } \\
\text { tration } \\
\text { /L) }\end{array}$ & $\begin{array}{r}\text { Mine } \\
\text { see } \\
\text { (36 mea } \\
\text { Conce } \\
\text { (m) }\end{array}$ & $\begin{array}{l}\text { water } \\
\text { oage } \\
\text { drements) } \\
\text { ttration } \\
\text { g/L) }\end{array}$ & $\begin{array}{r}\text { Tracei } \\
\text { (262 mea } \\
\text { Conce } \\
\text { (m) }\end{array}$ & $\begin{array}{l}\text { seepage } \\
\text { urements) } \\
\text { tration } \\
\text { (L) }\end{array}$ \\
\hline & Average & $\begin{array}{l}\text { Standard } \\
\text { deviation }\end{array}$ & Average & $\begin{array}{l}\text { Standard } \\
\text { deviation }\end{array}$ & Average & $\begin{array}{l}\text { Standard } \\
\text { deviation }\end{array}$ & Average & $\begin{array}{l}\text { Standard } \\
\text { deviation }\end{array}$ \\
\hline Bromide & 23.8 & 3.59 & 470 & 5.87 & 19.0 & 9.00 & $48.6^{\mathrm{a}}$ & $25.0^{\mathrm{a}}$ \\
\hline Chloride & 7.32 & 0.59 & 7.73 & 0.61 & 22.3 & 7.01 & 15.32 & 3.98 \\
\hline Fluoride & 2.60 & 0.47 & 2.70 & 0.057 & 2.17 & 0.42 & 2.31 & 0.541 \\
\hline Nitrate & 2.16 & 2.70 & 1.74 & 0.51 & 8.40 & 2.70 & 4.85 & 1.57 \\
\hline Phosphate & 0.024 & 0.078 & $0.000^{\mathrm{b}}$ & 0.000 & 0.000 & 0.000 & 0.011 & 0.060 \\
\hline Sulfate & 14.0 & 2.49 & 13.7 & 2.32 & 34.5 & 9.16 & 23.7 & 5.93 \\
\hline
\end{tabular}

${ }^{\mathrm{a}}$ The bromide concentration in the tracer seepage solutions increased over time during the nine days after the release of tracer solution.

The concentration then gradually decreased in response to the seven months of mine water flushing.

${ }^{\mathrm{b}}$ Below the detection limit presented in Table 4. 
Table 6. Summary of retardation factor and mass recovery in the column experiments

\begin{tabular}{|c|c|c|c|c|c|c|c|c|}
\hline \multirow[t]{2}{*}{ Sample } & \multicolumn{2}{|c|}{ Hanford sediment } & \multicolumn{2}{|c|}{ Oak Ridge sediment } & \multicolumn{2}{|c|}{ SRS subsurface } & \multicolumn{2}{|c|}{ Wisconsin soil } \\
\hline & $\begin{array}{c}\text { Retardatio } \\
\text { n factor }\end{array}$ & $\begin{array}{c}\text { Mass } \\
\text { recovery }\end{array}$ & $\begin{array}{c}\text { Retardatio } \\
\text { n factor }\end{array}$ & $\begin{array}{c}\text { Mass } \\
\text { recovery }\end{array}$ & $\begin{array}{c}\text { Retardation } \\
\text { factor }\end{array}$ & $\begin{array}{c}\text { Mass } \\
\text { recovery }\end{array}$ & $\begin{array}{c}\text { Retardation } \\
\text { factor }\end{array}$ & $\begin{array}{c}\text { Mass } \\
\text { recovery }\end{array}$ \\
\hline Tritium & 1.02 & 0.95 & 1.17 & 1.01 & 0.99 & 0.99 & 1.36 & 1.06 \\
\hline Fluoride & 13.74 & 0.98 & $>100^{\mathrm{a}}$ & 0.42 & 603 & 0.14 & $>44^{\mathrm{a}}$ & 0.09 \\
\hline Bromide & 1.01 & 1.02 & 2.48 & 1.00 & 1.87 & 0.98 & 1.05 & 0.95 \\
\hline Iodide & 1.05 & 1.01 & n.a. & 0.20 & 1.70 & 0.96 & 1.19 & 1.00 \\
\hline Iodate & 1.41 & 1.06 & $>100^{\mathrm{a}}$ & 0.16 & 49 & 0.83 & $>52^{\mathrm{a}}$ & 0.02 \\
\hline 2,6-DFBA & 1.01 & 1.01 & 1.55 & 1.01 & 1.82 & 0.98 & 1.11 & 0.96 \\
\hline 3,4-DFBA & 1.01 & 1.01 & 7.09 & 1.01 & 4.39 & 1.03 & 2.26 & 0.99 \\
\hline 3,4,5-TFBA & 1.04 & 1.00 & 6.25 & 0.96 & 3.62 & 1.04 & 2.16 & 0.96 \\
\hline PFBA & 1.01 & 1.01 & 1.11 & 1.04 & 1.57 & 0.97 & 1.14 & 0.96 \\
\hline
\end{tabular}

${ }^{a}$ To obtain the extent of sorption for tracers with large sorption, an alternate approach, such as a batch sorption study, is more appropriate than the column approach. 
Figure 1

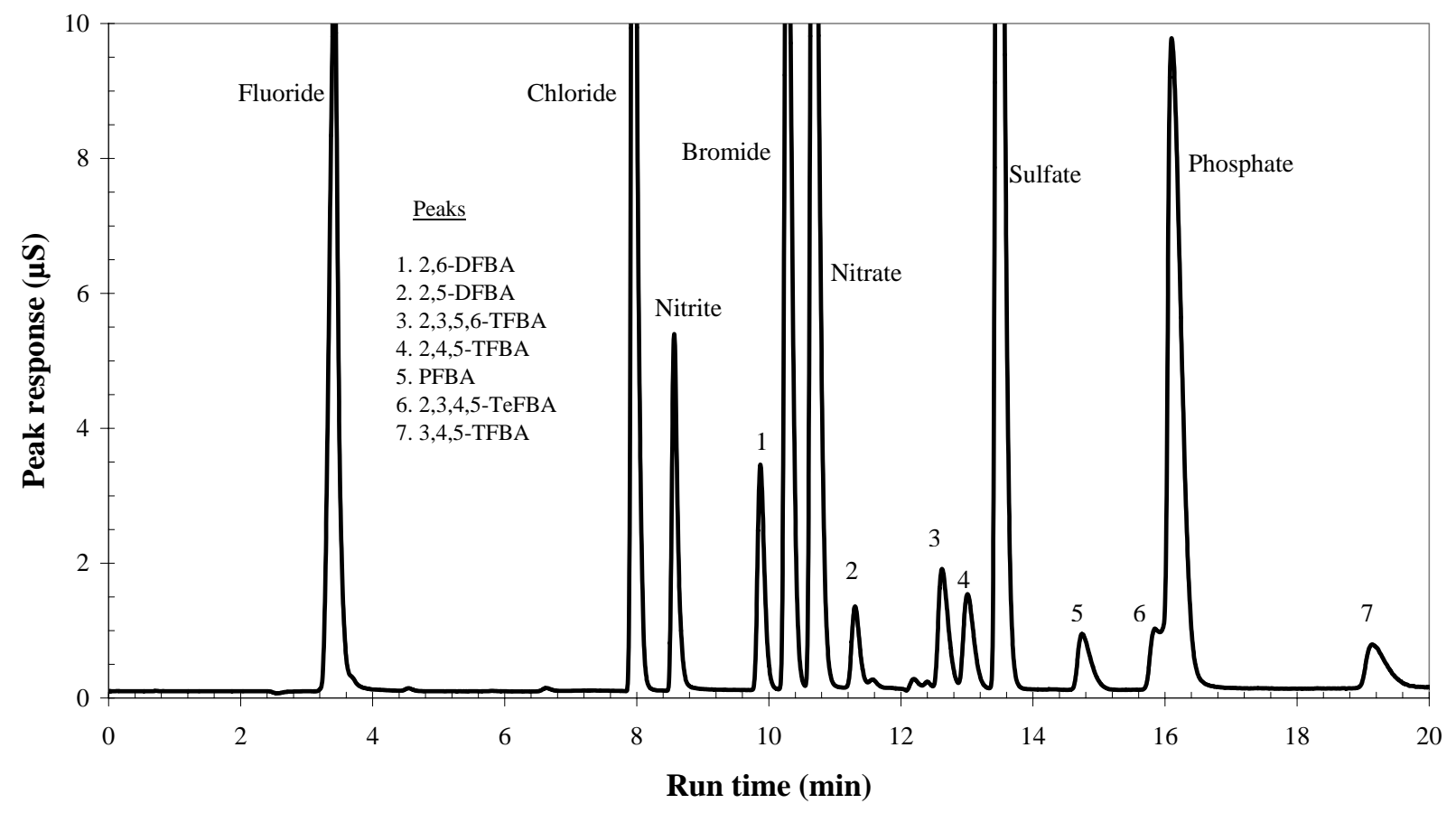


Figure 2

(a)

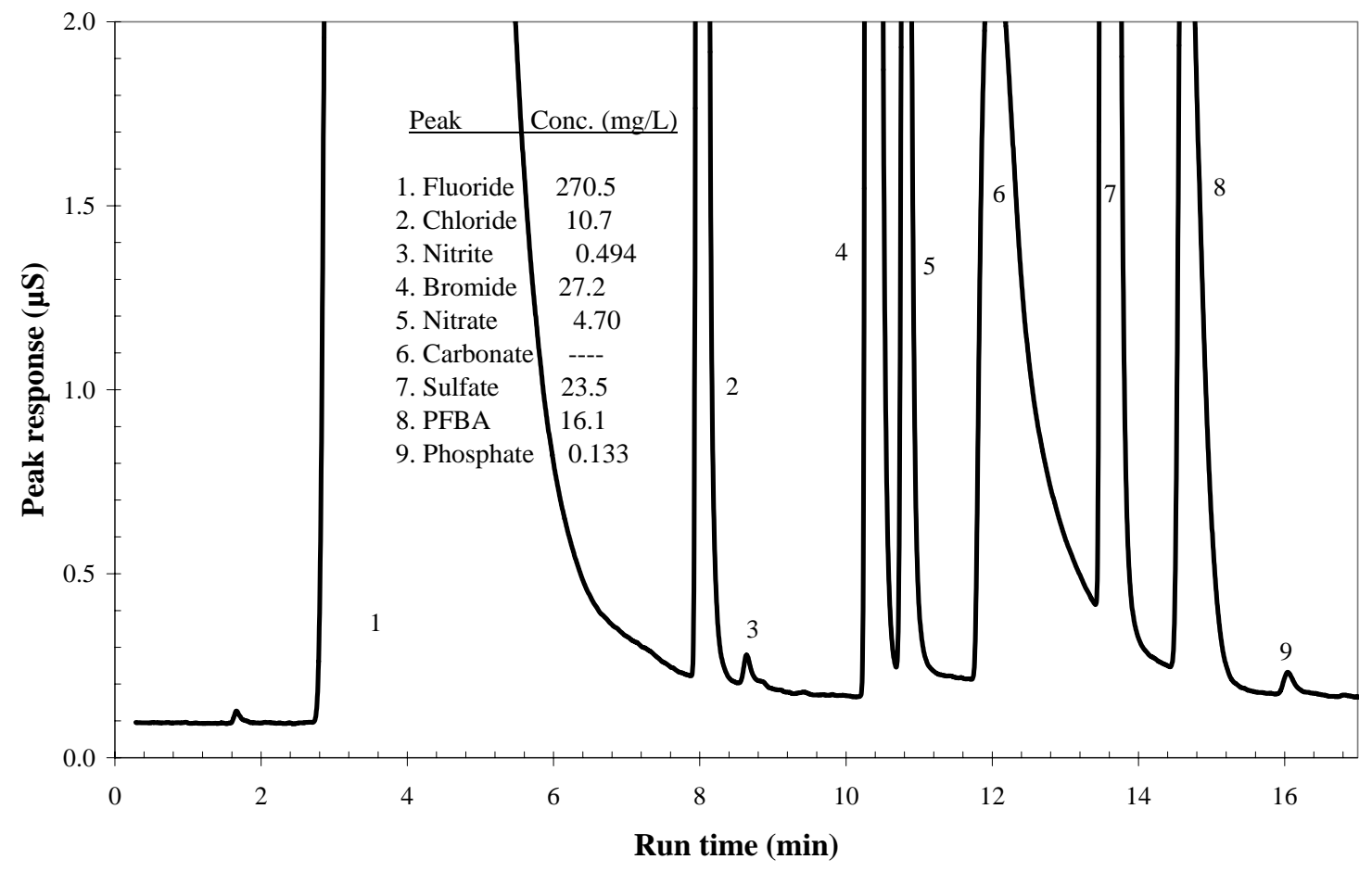

(b)

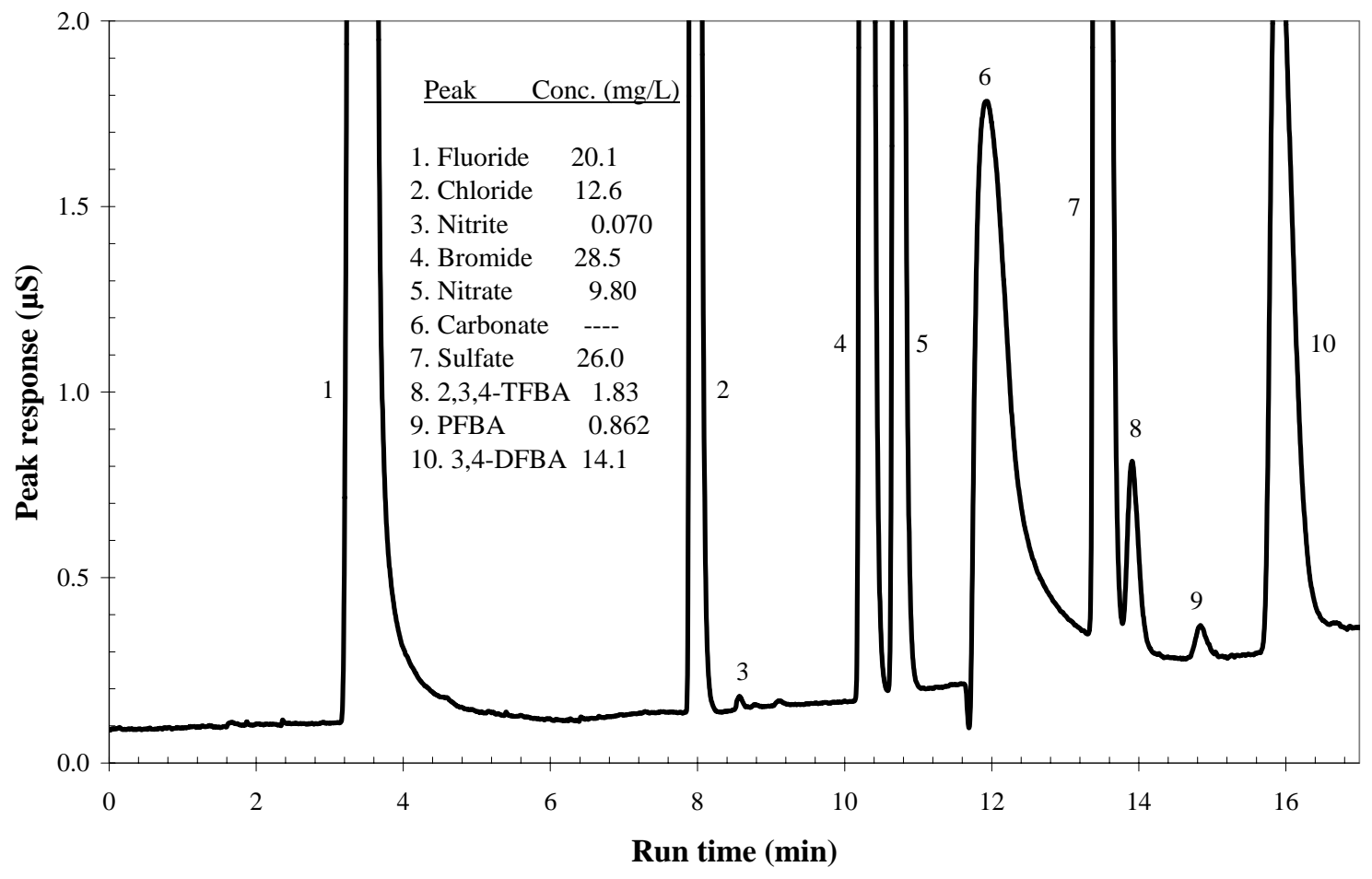


Figure 3

(a)

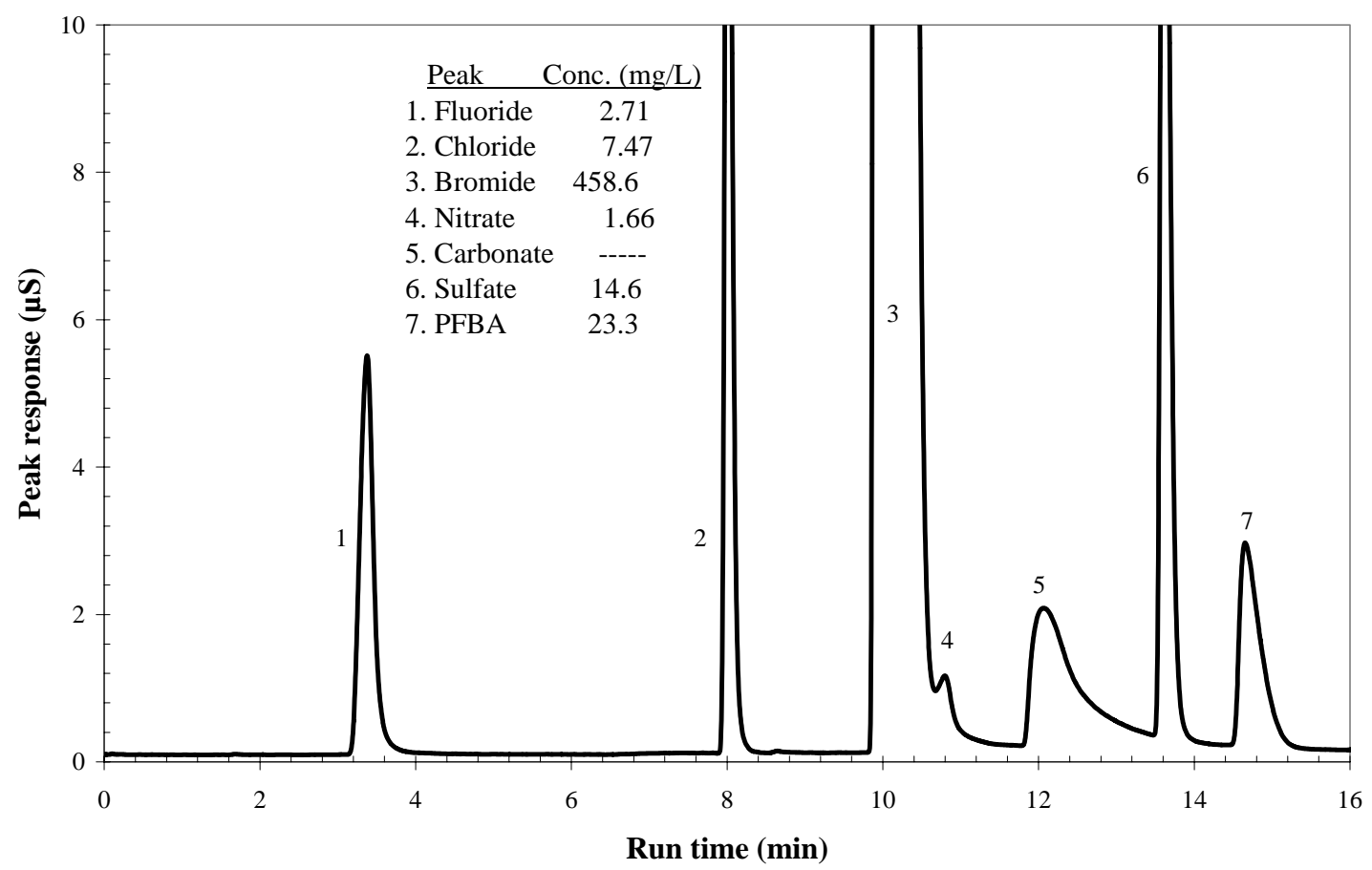

(b)

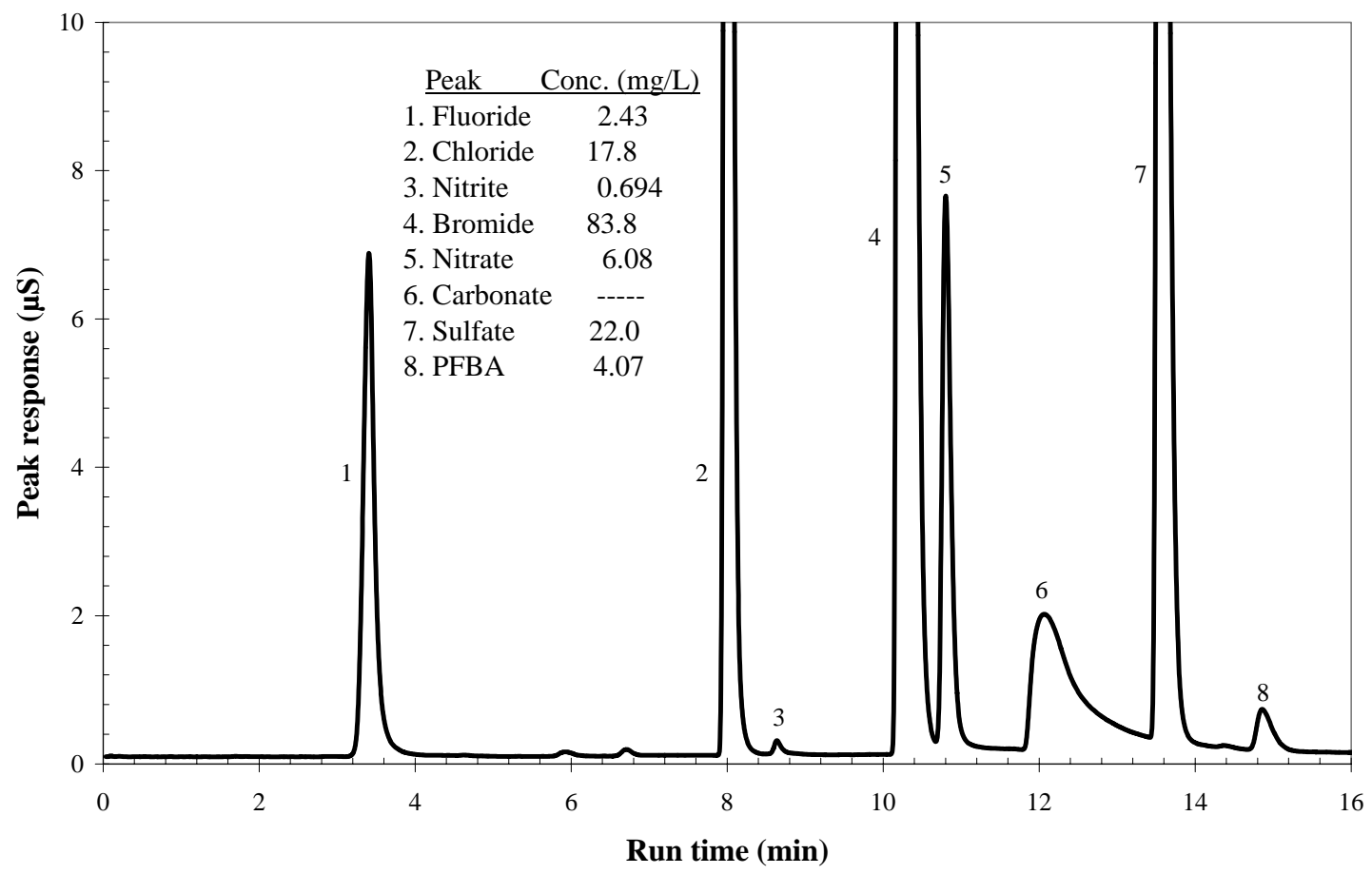


Figure 4

(a)

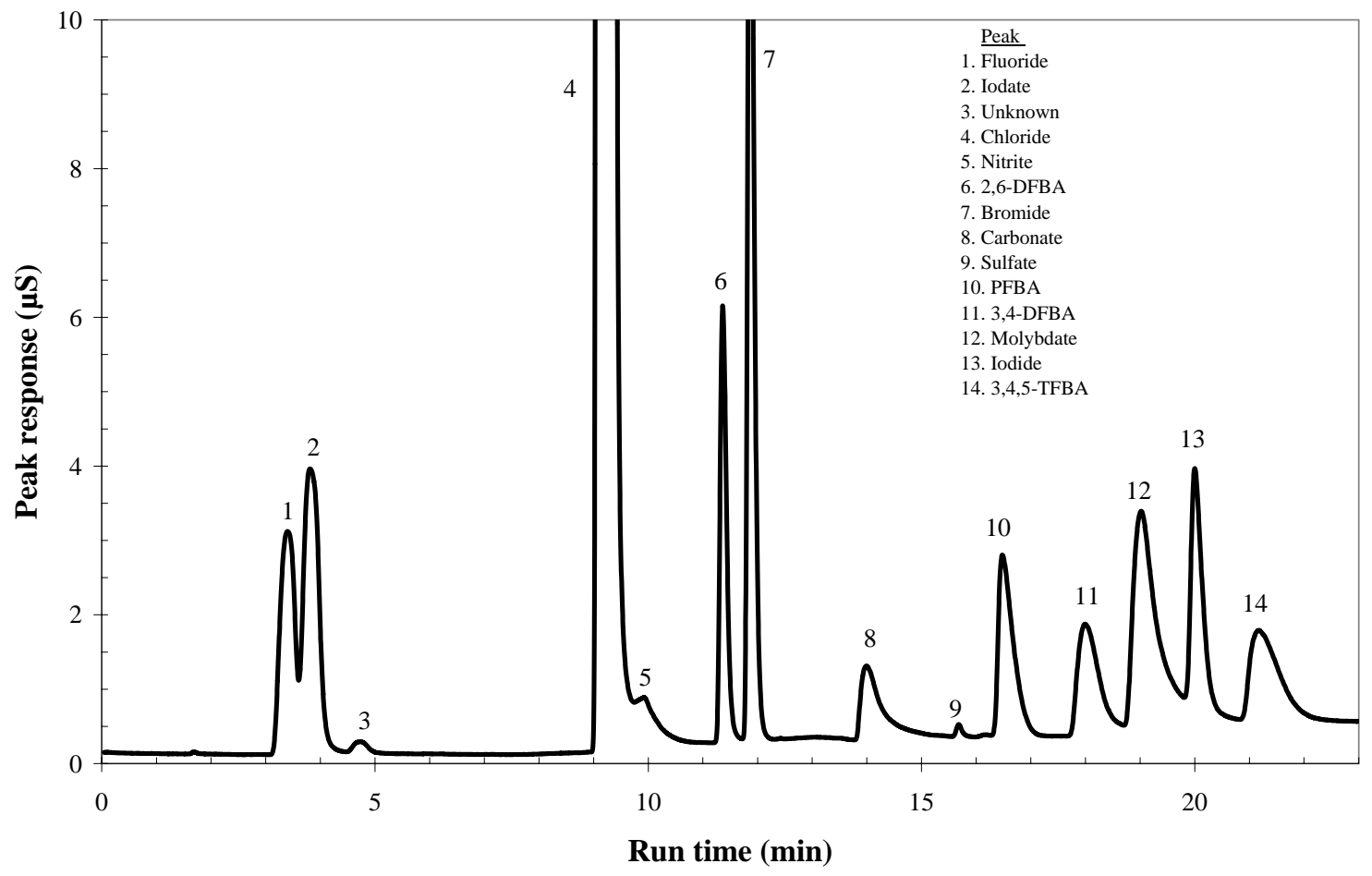

(b)

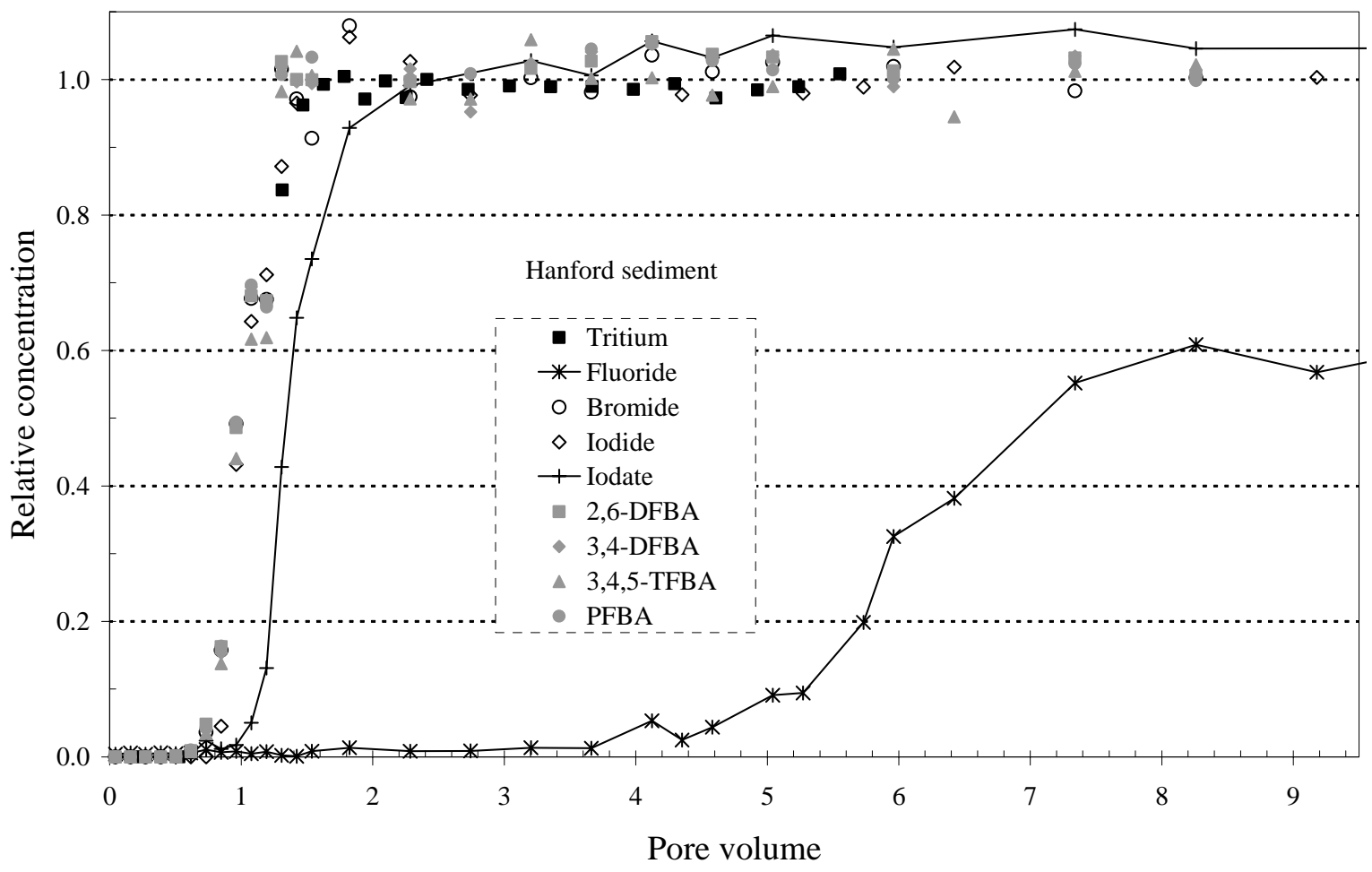


Figure 5

(a)

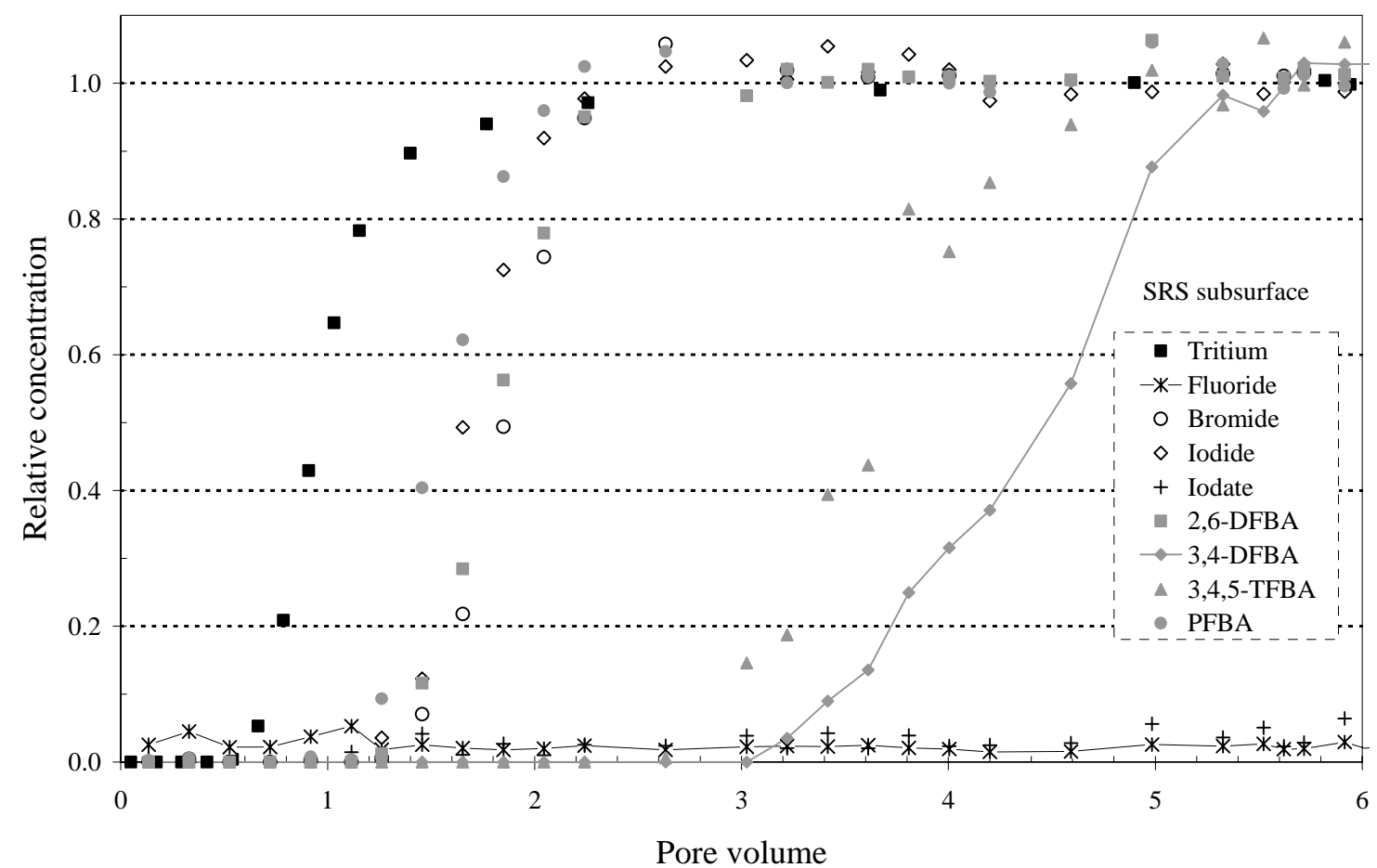

(b)

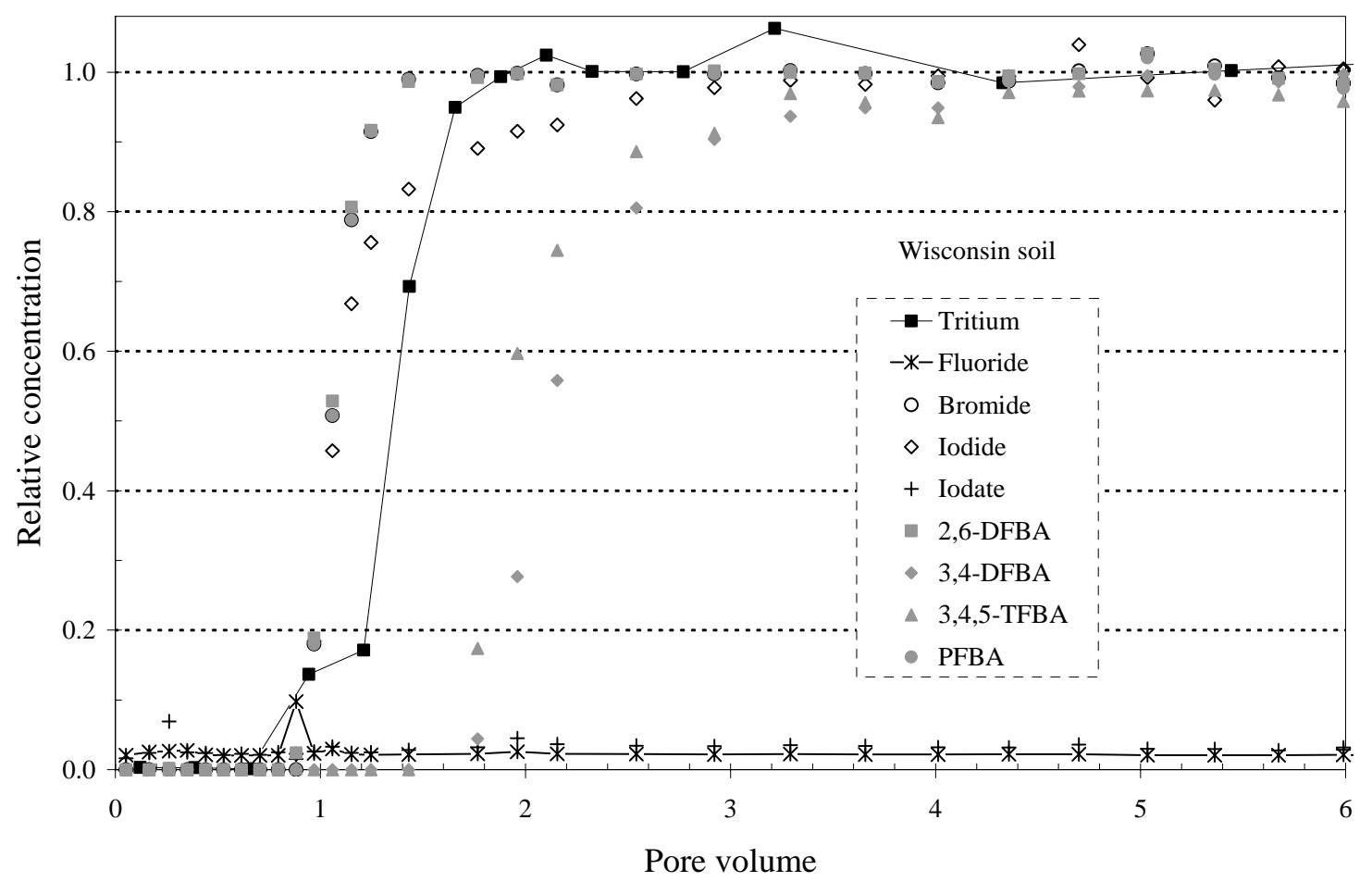

